\title{
Long-Term Maintenance of Channel Distribution in a Central Pattern Generator Neuron by Neuromodulatory Inputs Revealed by Decentralization in Organ Culture
}

\author{
Adi Mizrahi, ${ }^{1}$ Patsy S. Dickinson, ${ }^{1}$ Peter Kloppenburg, ${ }^{2}$ Valerie Fénelon, ${ }^{1}$ Deborah J. Baro, ${ }^{2}$ \\ Ronald M. Harris-Warrick, ${ }^{2}$ Pierre Meyrand, ${ }^{1}$ and John Simmers ${ }^{1}$ \\ 1 Laboratoire de Neurobiologie des Réseaux, Université Bordeaux I and Centre National de la Recherche Scientifique, \\ Talence 33405, France, and 2Department of Neurobiology and Behavior, Cornell University, Ithaca, New York 14853
}

Organotypic cultures of the lobster (Homarus gammarus) stomatogastric nervous system (STNS) were used to assess changes in membrane properties of neurons of the pyloric motor pattern-generating network in the long-term absence of neuromodulatory inputs to the stomatogastric ganglion (STG). Specifically, we investigated decentralization-induced changes in the distribution and density of the transient outward current, $I_{A}$, which is encoded within the STG by the shal gene and plays an important role in shaping rhythmic bursting of pyloric neurons. Using an antibody against lobster shal $\mathrm{K}^{+}$channels, we found shal immunoreactivity in the membranes of neuritic processes, but not somata, of STG neurons in $5 \mathrm{~d}$ cultured STNS with intact modulatory inputs. However, in $5 \mathrm{~d}$ decentralized STG, shal immunoreactivity was still seen in primary neurites but was likewise present in a subset of STG somata. Among the neurons displaying this altered shal localization was the pyloric dilator (PD) neuron, which remained rhythmically active in $5 \mathrm{~d}$ decentralized STG. Two-electrode voltage clamp was used to compare $I_{\mathrm{A}}$ in synaptically isolated $\mathrm{PD}$ neurons in long-term decentralized STG and nondecentralized controls. Although the voltage dependence and kinetics of $I_{A}$ changed little with decentralization, the maximal conductance of $I_{A}$ in PD neurons increased by $43.4 \%$. This increase was consistent with the decentralization-induced increase in shal protein expression, indicating an alteration in the density and distribution of functional A-channels. Our results suggest that, in addition to the short-term regulation of network function, modulatory inputs may also play a role, either directly or indirectly, in controlling channel number and distribution, thereby maintaining the biophysical character of neuronal targets on a long-term basis.

Key words: crustacean; stomatogastric ganglion; motor network; identified pyloric neuron; organ culture; decentralization; shal $\mathrm{K}^{+}$channel; shal immunodetection; voltage clamp
Neural network function depends critically on both synaptic connectivity and intrinsic membrane properties of component neurons (Marder and Calabrese, 1996; Stein et al., 1997). The intrinsic properties of each neuron are in turn determined by its specific membrane conductances and their distribution within different compartments of the neuron. Central pattern generators provide excellent models for studying the contributions of such cell-specific properties to the generation of appropriate behavioral output. The operation of these networks is optimized on a short-term basis by neuromodulators that act on both synapses and intrinsic membrane properties to alter the output of individ-

Received Jan. 31, 2001; revised June 21, 2001; accepted June 27, 2001.

This work was supported by the Région Aquitaine, a Chateaubriand Fellowship (A.M.), a National Institutes of Health Fogarty Senior Fellowship, a Guggenheim Fellowship, a Porter Fellowship from Bowdoin College, National Science Foundation Grant 9723885 (P.S.D.), and National Institutes of Health Grants NS38770 (D.J.B.), NS35631, and NS17323 (R.M.H.). We thank Jacqueline Chapron for expert assistance with organ cultures.

Correspondence should be addressed to Dr. John Simmers, Laboratoire de Neurobiologie des Réseaux, Université Bordeaux I and Centre National de la Recherche Scientifique-Unité Mixte de Recherche 5816, Avenue des Facultés, Talence 33405, France. E-mail: j.simmers@Inr.u-bordeaux.fr.

A. Mizrahi's present address: Department of Life Sciences, Ben Gurion University, Beer Sheva 84105, Israel.

P. S. Dickinson's present address: Department of Biology, Bowdoin College, Brunswick, ME 04011 .

D. J. Baro's present address: Institute of Neurobiology, Medical Sciences Campus, University of Puerto Rico, San Juan, PR 00901.

Copyright (C) 2001 Society for Neuroscience $\quad 0270-6474 / 01 / 217331-09 \$ 15.00 / 0$ ual neurons and thereby the network as a whole (Harris-Warrick and Marder, 1991; Pearson, 1993; Stein et al., 1997).

In addition to short-term adaptive influences, modulatory inputs play an important role in longer-term processes, such as the development of neural networks (Sillar et al., 1992, 1995; Fénelon et al., 1998b; Le Feuvre et al., 1999). Synaptic inputs likewise exert long-term control over their targets in the mature nervous system. Motoneurons, for example, determine the number and distribution of acetylcholine receptors on their target muscles both during development and in the adult (Fambrough, 1979; Lupa et al., 1995; Fischbach and Rosen, 1997).

We thus asked whether modulatory inputs are also responsible for maintaining the electrophysiological properties of individual neurons in the networks they modulate by exerting control over the distribution and density of ion channels in those neurons either directly (via second messenger signaling) or indirectly (by activity-dependent plasticity). For example, can the distribution of a channel that is expressed and modulated differentially in different cell types (Baro et al., 1997, 2000; Baro and HarrisWarrick, 1998; Harris-Warrick et al., 1998) be differentially altered in a single neuron in response to long-term changes in the modulatory environment? The well studied 14-member pyloric network of the crustacean stomatogastric nervous system (STNS) is an ideal system in which to address this question; it is highly modulated by descending axons in a single input nerve and can be maintained in organotypic culture, allowing assessment of slow 
changes in ion channel localization after removal of modulatory inputs.

One ionic current that is important in shaping neuronal firing is the voltage-dependent transient $\mathrm{K}^{+}$-current, $I_{\mathrm{A}}$. Within the stomatogastric ganglion (STG), $I_{\mathrm{A}}$ is encoded by the shal gene, which is expressed at different levels in the soma and dendrites of different neurons; this current is thus directly involved in determining cell-specific membrane properties of stomatogastric neurons (Baro et al., 1996b, 2000; Baro and Harris-Warrick, 1998). Additionally, these channels are subject to short-term modulation. Dopamine, for example, modulates $I_{\mathrm{A}}$ and consequently is important in determining the pyloric pattern expressed at any time (Harris-Warrick et al., 1995a,b; Kloppenburg et al., 1999; Peck et al., 1999). The lobster shal gene has been cloned (Baro et al., 1996a,b), and antibodies to the shal protein are available, allowing the distribution of shal $\mathrm{K}^{+}$-channels to be monitored (Baro et al., 2000).

To assess the extent to which shal channels are controlled by long-term actions of modulatory inputs, we removed these inputs from the pyloric network and, after $6 \mathrm{~d}$ in vitro, monitored changes in neuronal activity, distribution of the shal protein, and the amount and properties of $I_{\mathrm{A}}$ in a single neuron type, the pyloric dilator (PD). Our results show that shal expression is indeed affected by the removal of modulatory control.

Parts of this work have been published previously (Fénelon et al., 1998a).

\section{MATERIALS AND METHODS}

Preparations. Experiments were performed on male and female adult European lobsters, Homarus gammarus, that were purchased from a commercial supplier (Aiguillon Marée, Arcachon, France). Animals were kept in aerated recirculating seawater at $14-16^{\circ} \mathrm{C}$ for up to 3 weeks before use, during which time they were fed once a week.

Before dissection, animals were anesthetized on ice for $20 \mathrm{~min}$. The STNS (Fig. 1 $A$ ), including the STG, the interconnecting nerves, the motor nerves, and the associated commissural and esophageal ganglia, was dissected from the stomach wall, as described by Combes et al. (1993), and pinned in a Sylgard (Dow Corning, Midland, MI)-coated dish. In experiments requiring intracellular recordings, the STG was desheathed shortly before the experiment to allow access to neuronal somata. Preparations were superfused continuously with saline containing (in mM): $479.1 \mathrm{NaCl}, 12.7 \mathrm{KCl}, 13.7 \mathrm{CaCl}_{2}, 3.9 \mathrm{Na}_{2} \mathrm{SO}_{4}, 10.0 \mathrm{MgSO}_{4}$, 5.0 HEPES, pH 7.45, and maintained at $13^{\circ} \mathrm{C}$ with a Peltier device.

Organotypic culture. For preparations maintained in culture before recording, the stomach was cleaned by washing through $200-300 \mathrm{ml}$ of sterile saline containing $40 \mu \mathrm{g} / \mathrm{ml}$ penicillin/streptomycin (pen/strep) (Sigma P-3539; Sigma, St. Louis, MO) before the stomach was removed from the lobster. Then, the stomach was given two 10 min washes in cold antibiotic saline and pinned out on a sterile Sylgard-coated dish in antibiotic saline (pen/strep, $20 \mu \mathrm{g} / \mathrm{ml}$ ) under sterile conditions for the rest of the dissection. Control preparations were left intact, whereas the single input nerve to the STG, the stn, was cut in decentralized preparations. The isolated nervous system was subsequently maintained at $14^{\circ} \mathrm{C}$ in culture medium containing 50\% L-15 (Life Technologies, Gaithersburg, MD) with additional D-glucose $(1 \mathrm{gm} / 1)$, and salts were added to bring the concentrations to those of the saline. The medium was changed daily, with fresh antibiotics added each day (day 1 is the first day in culture) as follows: days 1 and 2, pen/strep, $20 \mu \mathrm{g} / \mathrm{ml}$; day 3, pen/strep, 25 $\mu \mathrm{g} / \mathrm{ml}$; day 4 and thereafter, gentamycin (Life Technologies), $0.2 \mathrm{mg} / \mathrm{ml}$. Under these conditions, in which the broader spectrum gentamycin was used after initial exposure to pen/strep, cultured stomatogastric nervous systems usually remained viable for at least $8 \mathrm{~d}$.

Electrophysiological recordings. Standard electrophysiological techniques were used in all experiments. Nerves were recorded extracellularly using custom built amplifiers and stainless steel electrodes isolated from the bath with petroleum jelly. Intracellular recordings were made using glass microelectrodes filled with a mixture of $2 \mathrm{M}$ potassium acetate (KAc) and $2 \times 10^{-2} \mathrm{M} \mathrm{KCl}(9-40 \mathrm{M} \Omega$ ) and an Axoclamp 2A or 2B amplifier (Axon Instruments, Foster City, CA). The PD neuron was
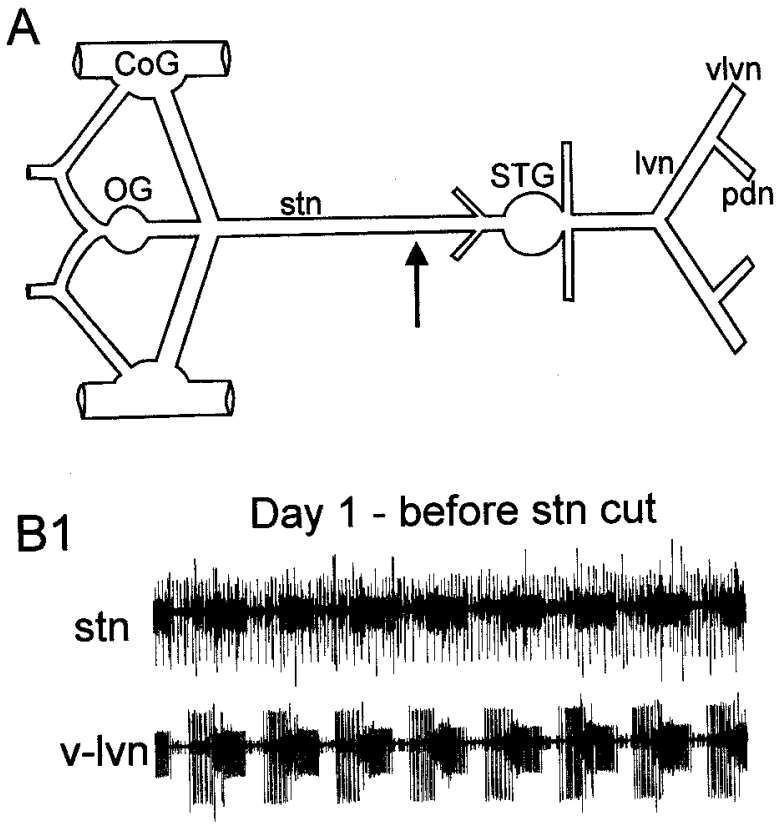

B2 Day $1-3 \mathrm{hr}$ after stn cut
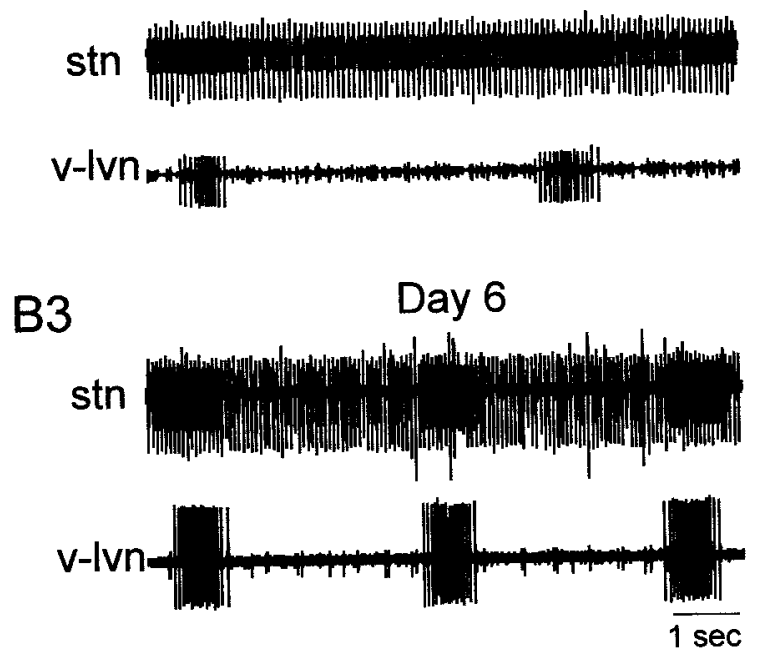

Figure 1. A, Schematic diagram of isolated lobster stomatogastric nervous system used in long-term organotypic culture. The sth was cut (arrow) in decentralized preparations and left intact in control preparations. CoG, Commissural ganglia; $O G$, esophageal ganglion; $S T G$, stomatogastric ganglion; stn, stomatogastric nerve; lvn, lateral ventricular nerve; $p d n$, pyloric dilator nerve; $v l v n$, ventral lateral ventricular nerve. $B$, Pyloric network activity recorded from indicated nerves on day 1 in vitro before $(B 1)$ and after (B2) the stn was cut, and from the same preparation on day 6 in organ culture (B3). (Note spikes from the tonically active anterior gastric receptor in all sth recordings.)

identified by a 1:1 correspondence of action potentials that were recorded intracellularly in the soma with those recorded extracellularly from the pyloric dilator motor nerve and by its characteristic phasing and synaptic input during the pyloric motor pattern.

Data other than voltage-clamp recordings were recorded on a PC with a data acquisition system (1401 CED; Cambridge Electronic Design, Cambridge, UK) and analyzed using Spike 2 (CED) software.

Voltage clamp of synaptically isolated PD neurons. PD neurons, isolated from chemical synaptic input by the presence of $\mathrm{CdCl}_{2}$, picrotoxin (PTX), and tetrodotoxin (TTX) in the bathing saline (see below), were impaled with two electrodes $(9-11 \mathrm{M} \Omega$, filled with $2.5 \mathrm{M} \mathrm{KCl})$ for voltage 
A
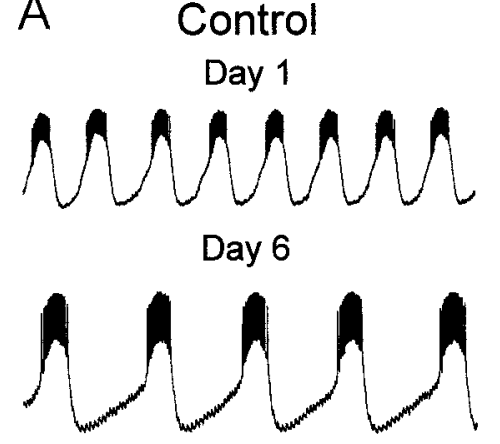

Decentralized

Day 1
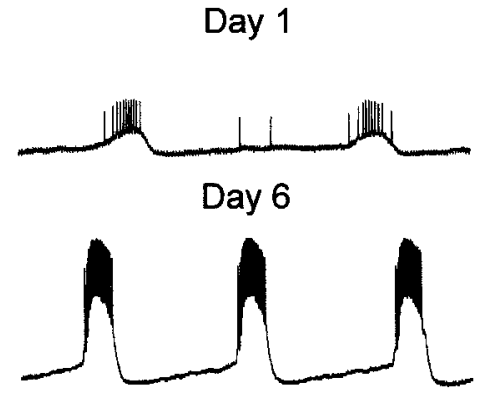

$\frac{\mathrm{s}}{1 \mathrm{~s}} 10 \mathrm{mV}$
B

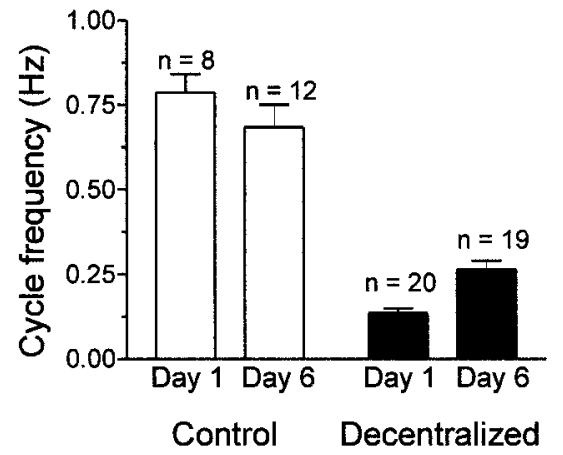

Figure 2. Long-term changes in spontaneous bursting of the PD neuron in control and decentralized STG. $A$, Intracellular recordings from PD neurons in control (stn intact, left) and decentralized (right) STG on days 1 and 6 in culture. Recordings are from PD neurons in four different STG. B, Cycle frequency measurements from indicated number of preparations in the two experimental conditions on days 1 and 6 . Cycle frequency in PD neurons from control preparations was similar on days 1 and 6 (open bars; ANOVA followed by a Bonferroni rank sum test; $p>0.05$ ), whereas PD neuron cycle frequency was significantly higher on day 6 than on day 1 in decentralized STG (black bars; ANOVA followed by a Bonferroni rank sum test; $p<0.05$ ). By day 6, average PD cycle frequency in decentralized preparations was $38 \%$ of the frequency in control preparations.

recording and current recording or injection, and voltage-clamped using an Axoclamp-2B amplifier. A Digidata 1200 interface and pClamp 6 software (Axon Instruments) were used to generate the voltage protocols and to acquire data. Data were sampled at $100 \mu \mathrm{sec}$ intervals and filtered at $1.5 \mathrm{kHz}$ with an eight-pole Bessel filter. Linear leakage and capacitative currents were digitally subtracted using a $\mathrm{P} / 6$ protocol (Armstrong and Bezanilla, 1974).

Measurements of the transient $\mathrm{K}^{+}$current. $I_{\mathrm{A}}$ was isolated using a combination of pharmacological blockade, voltage inactivation, and digital current subtraction protocols. Sodium currents were blocked by $10^{-7}$ м TTX. Calcium currents were blocked by $\mathrm{CdCl}_{2}\left(2-6 \times 10^{-4} \mathrm{M}\right)$. Hyperpolarization-activated inward current was blocked by $\mathrm{CsCl}(5 \times$ $\left.10^{-3} \mathrm{M}\right)$. Tetraethylammonium $\left(2 \times 10^{-2} \mathrm{M}\right)$ was used to block the sustained potassium current, $I_{\mathrm{K}(\mathrm{V})}$, and the calcium-dependent potassium current, $I_{\mathrm{O}(\mathrm{Ca})}$, simultaneously. $I_{\mathrm{O}(\mathrm{Ca})}$ was also indirectly eliminated when the $\mathrm{Ca}^{2+}$ currents were blocked by $\mathrm{CdCl}_{2}$. Currents from glutamatergic synapses were blocked by $5 \times 10^{-6}$ M PTX (Bidaut, 1980).

In our experiments, the PD neuron was not isolated from its electrically coupled network partners, which include the anterior burster (AB) and second PD neurons. However, we do not believe that electrical coupling contributed significantly to our voltage-clamp measurements of $I_{\mathrm{A}}$ because we never detected systematic differences in A-current amplitude between PD neurons with intact electrical coupling and preparations in which the $\mathrm{AB}$ and other $\mathrm{PD}$ neuron were previously photoablated (by intracellular injection of 5,6-carboxyfluorescein and illumination with blue light) (Miller and Selverston, 1979). This is almost certainly attributable to the fact that the space-clamped region of the cell does not extend to soma-distant neurites in which electrical coupling occurs (Graubard and Hartline, 1991).

For measurement of $I_{\mathrm{A}}$, the cell was held at $-50 \mathrm{mV}$, and two series of $10 \mathrm{mV}$ voltage steps between -70 and $+70 \mathrm{mV}$ were delivered. The first series, which evoked the residual non- $I_{\mathrm{A}}$ currents, had no prestep, whereas the second series had a $1.5 \mathrm{sec}$ prestep to $-120 \mathrm{mV}$ to maximally deinactivate $I_{\mathrm{A}}$. The first series was digitally subtracted from the second, giving a relatively pure $I_{\mathrm{A}}$ that could be completely abolished by $4 \times$ $10^{-3}$ M 4-aminopyridine. Although this digital subtraction procedure removes the contribution of active $I_{\mathrm{A}}$ at or below $-50 \mathrm{mV}$, this was typically much $<5 \%$ of the maximal conductance.

The voltage dependence of $I_{\mathrm{A}}$ activation was determined by converting the peak current to a peak conductance, $g$ (assuming $E_{\mathrm{K}}=-86 \mathrm{mV}$ ) (Hartline and Graubard, 1992). The resulting $g / V$ curve was fitted to a third-order $(n=3)$ and first-order $(n=1)$ Boltzmann equation of the form:

$$
g / g_{\max }=1 /\left(1+e^{-\left(V-V_{\text {act }}\right) / s}\right)^{n},
$$

where $g_{\max }$ is the maximal conductance and $s$ is a slope factor. For the third-order Boltzmann fit, $V_{\text {act }}$ is the voltage at which half-maximal activation of the individual gating steps occurs, assuming a third-order activation relation (Hodgkin and Huxley, 1952). For the first-order Boltzmann fit, $V_{\text {act }}\left(=V_{0.5}\right)$ is the voltage of half-maximal activation of the peak current.

Steady state inactivation of $I_{\mathrm{A}}$ was measured from a holding potential of $-50 \mathrm{mV}$. Voltage presteps $(1.5 \mathrm{sec})$ were delivered at $5 \mathrm{mV}$ increments from -120 to $0 \mathrm{mV}$, followed by a step to $+50 \mathrm{mV}$, and the peak current was measured. The data, scaled as a fraction of the calculated maximal conductance, were fitted to a first-order Boltzmann equation (Eq. 1 with $n=1$ ), based on the model of Hodgkin and Huxley (1952).

Immunocytochemistry and confocal microscopy. Detection of shal type transient $\mathrm{K}^{+}$channels was performed using indirect immunofluorescence. We used a rabbit anti-shal antibody that was generated against the carboxy portion of the lobster shal peptide (Baro et al., 2000). For shal detection, stomatogastric ganglia were fixed in $4 \%$ paraformaldehyde in $0.1 \mathrm{M}$ phosphate buffer, $\mathrm{pH} 7.4$, for $1-2 \mathrm{hr}$ at $4^{\circ} \mathrm{C}$ and then rinsed at least five times in PBS with $0.3 \%$ Triton X-100 (PBST) over $2 \mathrm{hr}$. Then, the tissue was incubated for $48 \mathrm{hr}$ in the primary antibody diluted (final concentration, $0.5 \mu \mathrm{g} / \mathrm{ml}$ ) in PBST with $5 \%$ normal goat serum (NGS). After $2 \mathrm{hr}$ of PBST rinsing, the tissue was incubated for an additional 24 $\mathrm{hr}$ in goat anti-rabbit fluorescein (Sigma, St. Louis, MO)-conjugated, Texas Red (Vector Laboratories, Burlingame, CA)-conjugated, or Cy5 (Jackson ImmunoResearch)-conjugated Igs (1:200 in PBST with 10\% NGS). Finally, the tissue was thoroughly rinsed in PBS (2 hr), dehydrated (in a 30, 50, 70, 90, 95, and $100 \%$ ethanol series, 10 min each), cleared in pure methylsalicylate (Sigma) and mounted with permount (Fisher Scientific, Houston, TX) on microscope slides. Controls included omission of primary antibody, incubation in primary antibody that had been preabsorbed with the shal fusion protein $\left(10 \mu \mathrm{g} / \mathrm{ml}\right.$, overnight at $\left.4^{\circ} \mathrm{C}\right)$, and incubation in primary antibody followed by an inappropriate secondary antibody. No specific staining was seen in these controls.

For immunodetection of shal on cell bodies and neurites of identified PD neurons, dextran tetramethylrhodamine (D-3308; Molecular Probes, Eugene, OR) was injected into an electrophysiologically identified PD neuron by iontophoresis. The tip of the microelectrode was filled with a $5 \%$ solution of the dye diluted in $0.2 \mathrm{M} \mathrm{KAc}$, then backfilled with $0.2 \mathrm{M}$ KAc. The dye was injected intrasomatically by passing depolarizing current pulses $(5 \mathrm{nA}, 200 \mathrm{msec}, 4 \mathrm{~Hz})$ for at least $45 \mathrm{~min}$. After injection, the dye was allowed to migrate into the neuropilar arborization of the cell for $\sim 1 \mathrm{hr}$. Then, nervous systems were processed for the detection of shal as described above, using Cy5-labeled secondary antibody.

All preparations were viewed and imaged on a Leica TCS 4D laser scanning confocal microscope equipped with a krypton-argon mixed gas laser through $20 \times$ air interface objective lens and $50 \times$ water-immersion objective lenses. The filter blocks used for double labeling were standard Leica-supplied and were optimized for the separation of tetramethyl rhodamine isothiocyanate and Cy5. All confocal acquisitions were blind to experimental treatment. Optical sections were taken every $1-2.5 \mu \mathrm{m}$, and images were compiled into maximum projection "z-series." All 

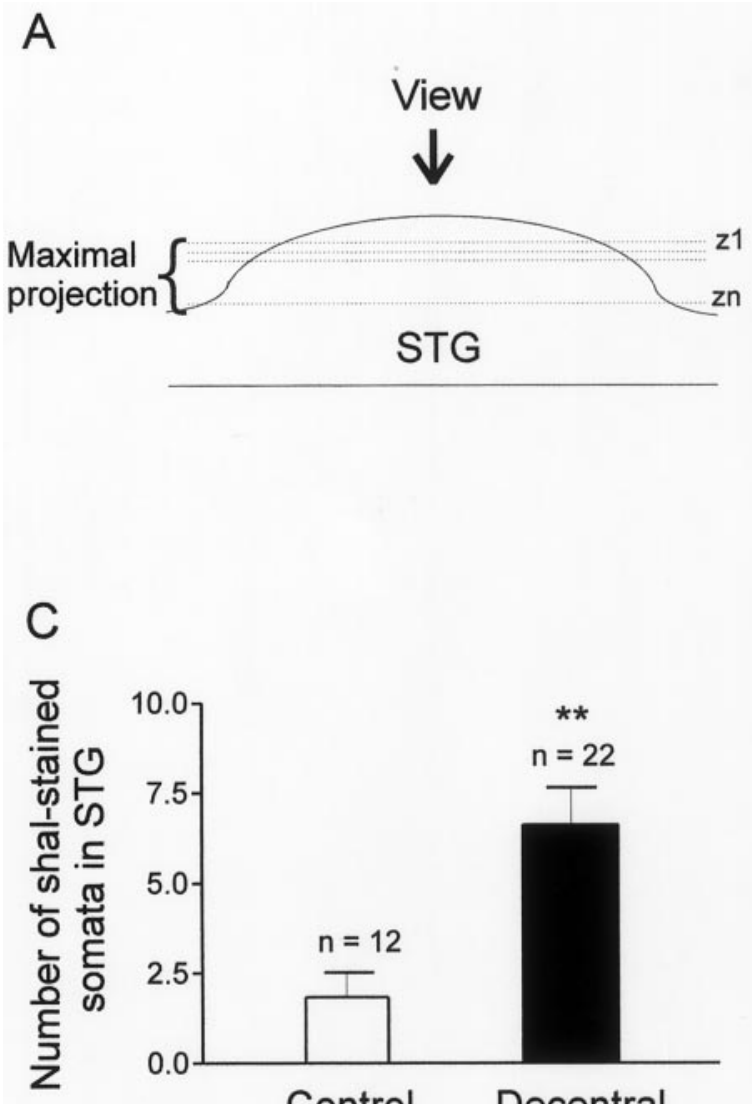

B

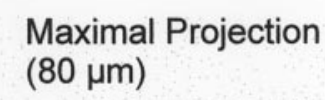

Decentralized day 5

\author{
Maximal Projection \\ $(68 \mu \mathrm{m})$
}

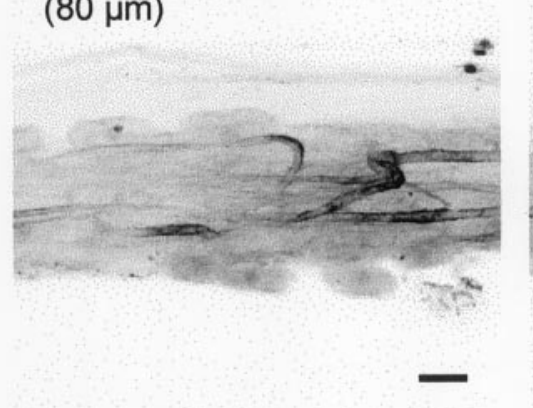

D Control

$\mathbf{z 1}$

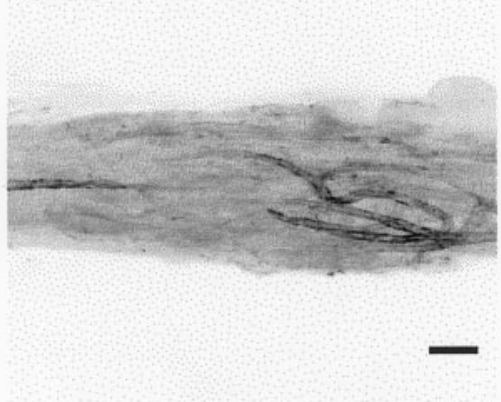

Decentralized day 5

z1

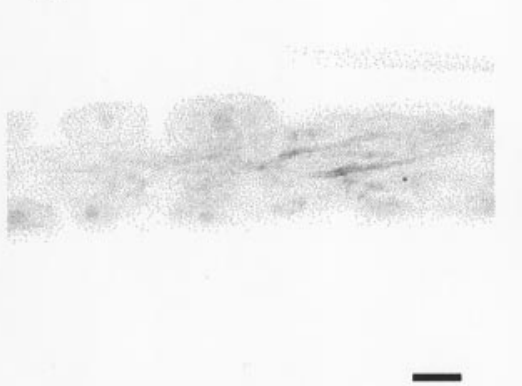

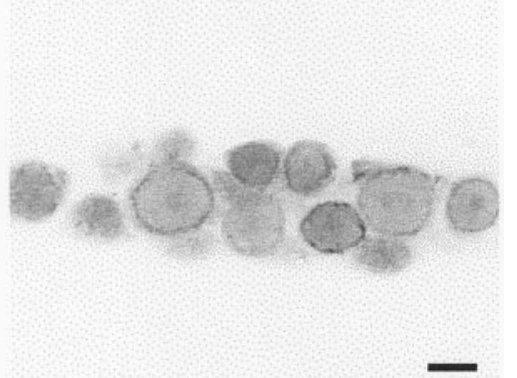

Figure 3. Unidentified STG somata, but not neurites, show an increase in the expression of shal-like immunoreactivity after decentralization. $A$, Diagram showing planes of confocal images illustrated in $B$ and $D$. $B$, Maximal projection $(A)$ showing neurites that exhibit shal-like immunoreactivity in both control (left) and decentralized (right) STG after $5 \mathrm{~d}$ in culture. $C$, Number of shal-stained somata in the STG increased after decentralization $\left(t\right.$ test, $\left.{ }^{* *} p<0.05\right)$. D, Single optical section taken at plane $z 1$ in $A$, showing absence of staining in control somata (left) but presence of staining in long-term decentralized somata (right). Scale bars, $50 \mu \mathrm{m}$.

figures of immunostaining were produced with Photopaint and CorelDraw software and printed on an Epson Stylus 600 printer.

Statistical analysis. For single nonpairwise comparisons, Student's $t$ tests were used to assess statistical significance. To compare multiple data sets, we used an ANOVA with post hoc protected $t$ tests (Bonferroni's). Significances were accepted at $p=0.05$. Throughout this paper, calculated ranges are reported as SEMs.

\section{RESULTS}

When isolated in organ culture, the STNS of the European lobster, Homarus gammarus, continued to generate a pyloric rhythm for at least 8 d. However, when the STG was decentralized by cutting or blocking conduction in the stn (Fig. $1 A$ ), most elements of the pattern fell silent, and only the PD and the electrically coupled $\mathrm{AB}$ neurons continued to discharge in regular bursts (Fig. $1 B$ ). Within the first $4-18 \mathrm{hr}$ after decentralization, the cycle frequency dropped to very low levels (Fig. 1B2), and rhythmic oscillations generally ceased for at least $20 \mathrm{~min}$. With time in culture, however, we saw partial recovery of rhythmic activity in the PD neurons; although they continued to show irregular periods of 5-30 min during which no rhythmic activity was expressed, the majority of the time, these preparations were actively cycling. The cycle frequency during such active periods increased significantly with time (ANOVA and Bonferroni's $t$ test, $p<0.05)$ from $0.14 \pm 0.06 \mathrm{~Hz}(n=20$; day 1 in culture, recorded $100 \mathrm{~min}$ to $15 \mathrm{hr}$ after decentralization) to $0.26 \pm 0.11$
Hz on days $6-8$ in culture $(n=19)$ (Fig. $2 B$; also see Fig. $1 B 3)$. No difference in oscillation frequency was seen between preparations recorded on day 6 and those recorded on subsequent days.

Control preparations, which were placed in culture but with an intact $s t n$, continued to generate a triphasic rhythm throughout the time in culture. In contrast to the case in decentralized preparations, cycle frequency in the control preparation (Fig. 2A) slowed somewhat but, when averaged over a number of preparations, did not differ significantly when recorded on day $1(n=8)$ or on days $6-8$ in culture $(n=12)$ (Fig. $2 B$ ). Thus, although the oscillation frequencies in the PD neurons in decentralized and control preparations approached one another with time in culture, they did not converge on a common value, as previously reported in the spiny lobster, Jasus lalandii (Thoby-Brisson and Simmers, 1998).

The PD neurons (along with the AB interneuron) (Fig. 1, stn trace) were the only pyloric neurons that remained active in long-term decentralized preparations. PD oscillations continued in decentralized preparation even after removal of the AB neuron (our unpublished observations). Thus, it seemed likely that the observed oscillations in decentralized preparations resulted from an alteration in intrinsic conductances that would both alter their characteristics of bursting and support unconditional bursts in these neurons in the absence of neuromodulators. We chose to 
A Control STG
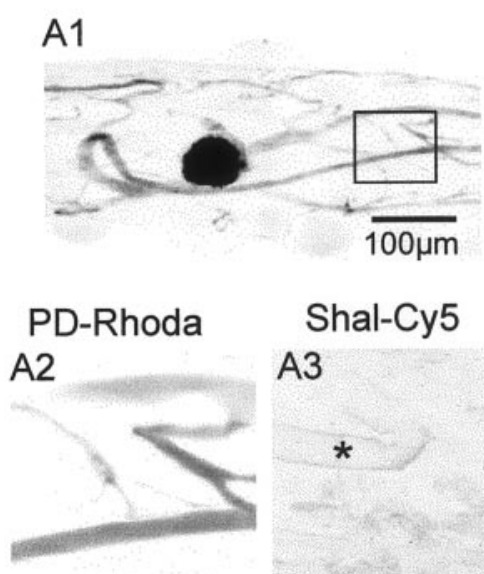

A3

A4

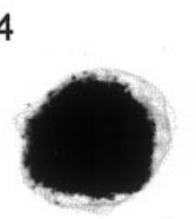

B Decentralized STG

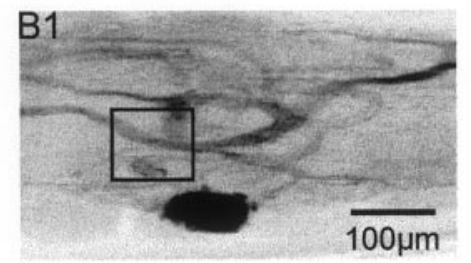

PD-Rhoda

B2
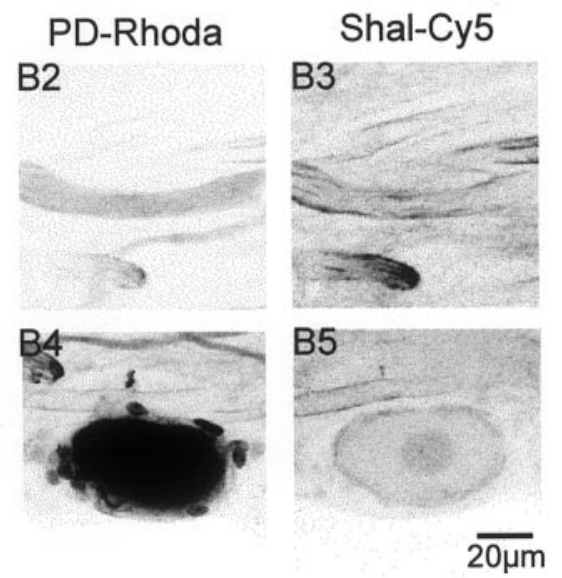

C

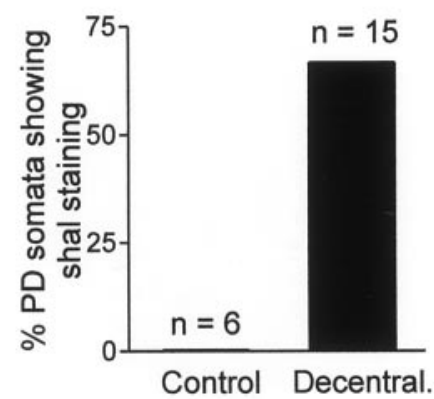

Figure 4. Identified PD neurons express shal-like immunoreactivity after STG decentralization. $A$, Double fluorescent staining of a single PD neuron injected with dextran tetramethylrhodamine $(A 1, A 2, A 4)$ and treated with Cy5-labeled anti-shal antibody $(A 3, A 5)$ in a control preparation. Images are maximal projections composed of six optical sections representing a total depth of $12 \mu \mathrm{m}$. Image stacks in $A 2$ and $A 3$ were acquired at the level of neurites in the STG $(A 1$, square), whereas $A 4$ and $A 5$ were taken at the level of STG somata. No shal staining was evident on either the PD cell body or its neurites. * indicates unidentified neurite that showed shal staining. $B$, Similar double staining to that shown in $A$, but from a decentralized preparation. Shal staining was present on both the somata (B5) and large neurites (B3) of the rhodamine-injected PD neuron. $A 1$ and $B 1$ are at same scale, as are $A 2-5$ and $B 2-5$. $C$, Percentage of identified PD neuron somata expressing shal-like immunoreactivity was higher in long-term decentralized STG relative to control preparations.

investigate one channel type, the shal transient potassium channel, which is important in shaping the membrane oscillations in the PD neuron (Kloppenburg et al., 1999) and for which specific antibodies are available (Baro et al., 2000). We thus examined long-term changes in this channel using two approaches, immunocytochemical detection of the shal protein and voltage-clamp analysis of the A-type transient potassium current $\left(I_{\mathrm{A}}\right)$ carried by this channel.

\section{Shal channel distribution in decentralized and control STG}

Anti-shal staining was detected on neuritic processes in all STG that were examined, including both control and decentralized ganglia. This anti-shal staining appeared as a thin band on either side of the process and was present in neurites of various dimensions throughout the neuropil (Fig. $3 A, B$ ). Although we did not quantify the size distribution of labeled neurites, there were no apparent differences in the sizes of neurites preferentially labeled in control versus decentralized preparations. Additionally, although it was not possible to quantify the intensity of immunofluorescent staining, qualitative observations did not suggest any significant difference in anti-shal staining intensity between neurites in control and decentralized STG (Fig. 3B). Thus, decentralization per se did not appear to alter the distribution of shal channels on central neurites of STG neurons.

In contrast, decentralization provoked a significant increase (Fig. $3 C)\left(t\right.$ test, $\left.{ }^{* *} p<0.01\right)$ in the number of STG neurons labeled by anti-shal antibodies in their somata, which appeared as a thin ring encircling the somata (Fig. 3D, right panel). In control preparations $(n=12)$, only $1.83 \pm 0.66$ STG neurons showed anti-shal staining (Fig. 3C). By comparison, $6.62 \pm 1.02$ somata were stained in long-term decentralized ganglia $(n=22)$.

\section{Shal channel redistribution in PD neurons}

To determine whether these changes in shal channel distribution specifically involved the PD neurons, shal immunodetection was performed on control and decentralized STG cultures in which one or both PD neurons had been previously injected with a fluorescent dye (see Materials and Methods). Shal-like immunoreactivity was detected in the neurites of identified PD neurons (Fig. 4A1,2) in only 1 of 4 control STG (Fig. 4A3), whereas 10 of 13 PD neurons (Fig. 4B1,2) in decentralized STG displayed shal staining (Fig. 4B3). Control PD neuron somata (Fig. 4A4) $(n=$ 6) never expressed shal-like staining (Fig. 4A5,C), whereas after removal of neuromodulatory inputs, $67 \%$ of PD neuron cell bodies (Fig. $4 B 4)(n=15)$ displayed distinct anti-shal like immunoreactivity (Fig. 4B5,C).

\section{Voltage-clamp analysis of the transient $\mathrm{K}^{+}$current}

These immunocytochemical experiments suggested that decentralization of the STG induces a redistribution and/or new expression of shal channels, which could in turn increase the transient voltage-activated $\mathrm{K}^{+}$current in the PD neuronal membrane. To determine whether $I_{\mathrm{A}}$ was indeed enhanced after STG decentralization, we performed voltage-clamp studies on synaptically isolated PD cells and compared $I_{\mathrm{A}}$ in control ganglia (intact stn) maintained in culture for at least $5 \mathrm{~d}$ to that in 
Figure 5. Transient $\mathrm{K}^{+}$current, $I_{\mathrm{A}}$, in $\mathrm{PD}$ neurons was larger in decentralized preparations $(B, C)$ than in control $(A) . B$ and $C$ are from separate decentralized preparations to illustrate variability in recorded time constants. $I_{\mathrm{A}}$ was isolated by pharmacological blockade and digital subtraction (see Materials and Methods). Holding potential, $-50 \mathrm{mV} . A 1, B 1, C 1$, Steady-state activation: current responses to voltage steps $(500 \mathrm{msec})$ between -70 and $+50 \mathrm{mV}$ in $10 \mathrm{mV}$ increments. $A 2, B 2, C 2$, Steadystate inactivation: currents recorded in response to a test pulse $(+50 \mathrm{mV}, 400 \mathrm{msec})$ from prepulses ranging from -120 to -20 $\mathrm{mV}$ in $5 \mathrm{mV}$ increments.
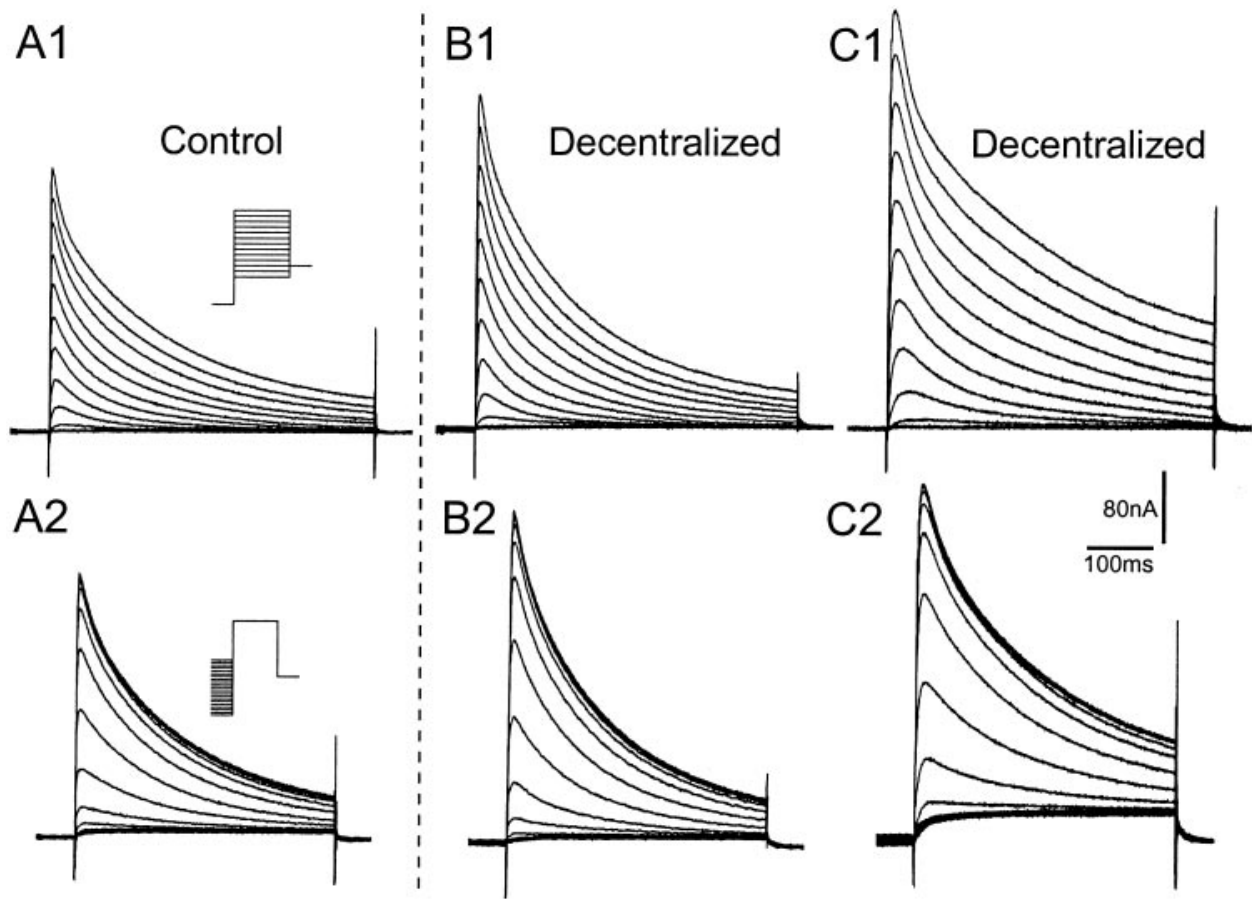

decentralized preparations maintained under the same culture conditions after the stn was cut.

In both control and decentralized preparations, $I_{\mathrm{A}}$ activated with voltage steps above $-50 \mathrm{mV}$ (Figs. $5 A, B, 6 D$ ). This current in PD neurons displayed typical features of $I_{\mathrm{A}}$; it was transient and decayed because of inactivation during a maintained depolarizing voltage step; both activation and inactivation kinetics were voltage dependent (Connor and Stevens, 1971; Kloppenburg et al., 1999). The time-to-peak current, which we measured as an indicator of activation kinetics, decreased with increasing command potentials (Fig. $6 A$ ). $I_{\mathrm{A}}$ inactivates with two time constants, $\tau_{1}$ (short) and $\tau_{2}$ (long), both of which decreased when command voltages were increased (Fig. 6A-C). The conductance-voltage relationship for steady-state activation (Fig. $6 D$ ) was determined from the peak currents evoked by each voltage step. This curve showed typical voltage dependence for activation for $I_{\mathrm{A}}$, and was fitted to a third-order Boltzmann equation. The fit showed halfmaximal activation for each of the individual gating steps at $-41.7 \mathrm{mV}$, leading to half-maximal activation of the peak current $\left(V_{0.5}\right)$ at $-17.3 \mathrm{mV}$. The voltage dependence of steady-state inactivation (Fig. 6D) was well fitted by a first-order Boltzmann equation, with a voltage for half maximal inactivation of -63.2 $\mathrm{mV}$. These parameters for $I_{\mathrm{A}}$ in the PD neuron were in good agreement with those described by Baro et al. (1997) and Kloppenburg et al. (1999) for $I_{\mathrm{A}}$ in the PD neurons of the California spiny lobster, Panulirus interruptus.

The time-to-peak and the two time constants for inactivation $\left(\tau_{1}\right.$ and $\left.\tau_{2}\right)$ did not differ significantly between control and decentralized preparations (Fig. $6 A-C$ ). It is noteworthy, however, that the $I_{\mathrm{A}}$ recordings from the decentralized preparations showed a larger variation in these three parameters. This is illustrated by the voltage-clamp recordings in Figure 5, $B$ and $C$, showing $I_{\mathrm{A}}$ in PD neurons from two different decentralized preparations. The current in the neuron of Figure $5 B$ illustrates the more typical kinetics, seen in six of eight preparations. In contrast, Figure $5 C$ is from a decentralized preparation with slower kinetics, showing a longer time-to-peak and slower time constants for inactivation; such current was observed in two of eight decentralized preparations.

Likewise, neither the small postdecentralization shift in the voltage for half-maximal activation (from $-17.3 \pm 2.9$ to $-12.5 \pm$ $1.9 \mathrm{mV}$ ) (Fig. 6D) nor the shift for half-maximal inactivation (from $-63.2 \pm 1.7$ to $-61.3 \pm 1.8 \mathrm{mV}$ ) (Fig. $6 D$ ) was significant. However, $I_{\mathrm{A}}$ was significantly larger in long-term decentralized preparations than in control preparations (Figs. $5 A-C, 6 E$ ), with the maximal current at $+70 \mathrm{mV}$ increased by $43.4 \%(p<0.01)$ (Fig. 6F).

\section{DISCUSSION}

The aim of this study was to assess whether modulatory inputs to neuronal networks, in addition to exerting short-term modulatory control, are responsible for establishing and maintaining the biophysical properties of target network neurons. To this end, we chose to investigate the effects of the prolonged absence of modulatory inputs on the pyloric motor pattern-generating network in the lobster stomatogastric system, which has proven to be an excellent model for the study of neuromodulation (HarrisWarrick et al., 1992; Simmers et al., 1996). Short-term plasticity in the pyloric network results from changes both in synaptic interactions within the network and in intrinsic membrane properties of pyloric neurons (Harris-Warrick and Marder, 1991; HarrisWarrick et al., 1992, 1998; Marder and Calabrese, 1996).

The transient $\mathrm{K}^{+}$current, $I_{\mathrm{A}}$, plays an important role in controlling the motor output of the pyloric network by shaping oscillations in individual neurons. $I_{\mathrm{A}}$, which contributes to the timing of action potentials in spike trains and is important in determining the time course of postinhibitory rebound, has been extensively characterized on a biophysical level (Connor and Stevens, 1971; Graubard and Hartline, 1991; Golowasch and Marder, 1992; Tierney and Harris-Warrick, 1992; Harris-Warrick et al., 1995a,b, 1998; Kloppenburg et al., 1999; Peck et al., 1999). The lobster shal gene, which is responsible for $I_{\mathrm{A}}$ in crustacean pyloric neurons, has been cloned, and can now be localized using immunocytochemical techniques (Baro et al., 1996a,b, 1997, 2000; 


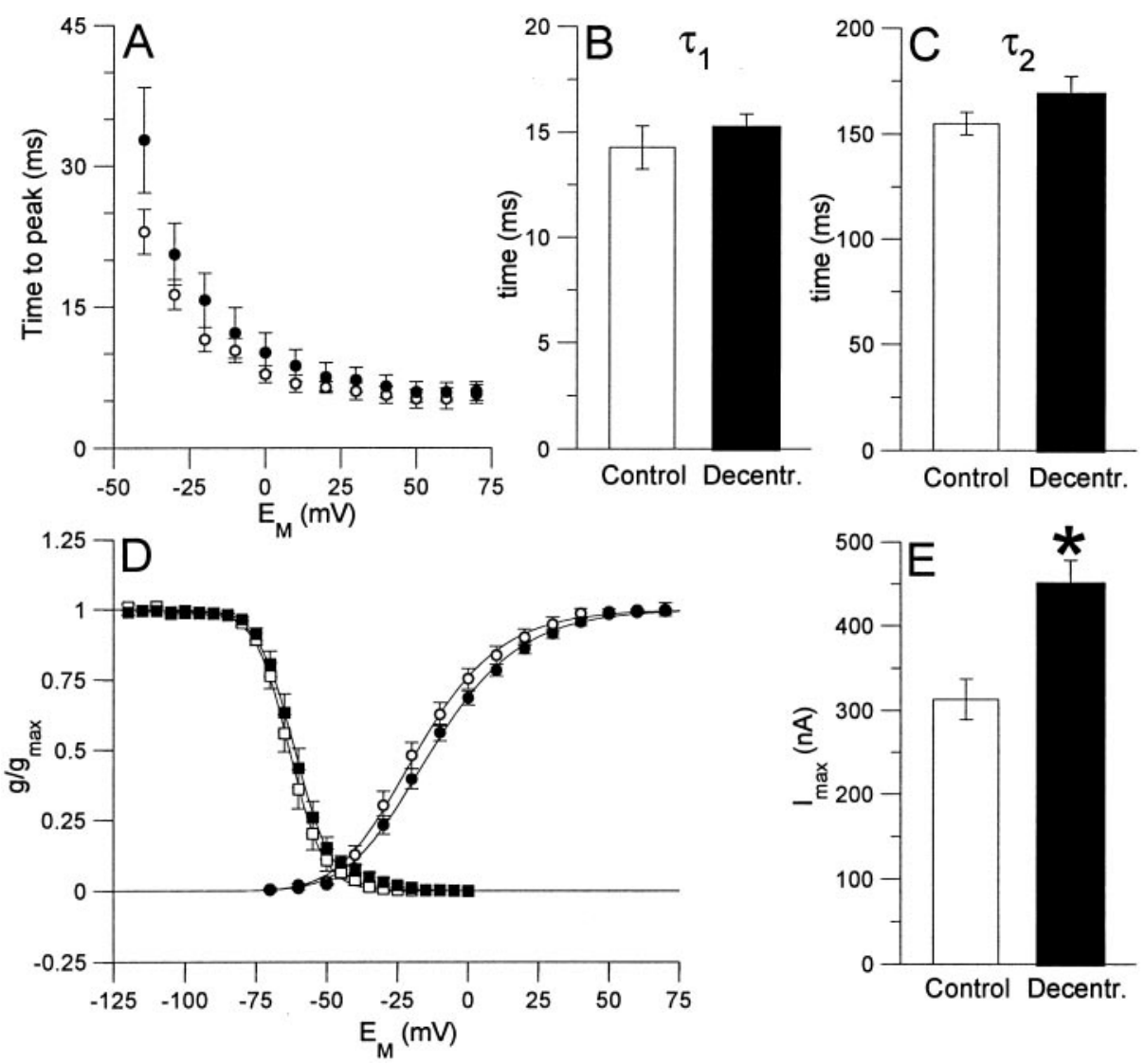

Figure 6. Effect of decentralization on parameters of $I_{\mathrm{A}}$ in PD neurons after $6 \mathrm{~d}$ in organ culture. All values are means \pm SEM (control preparation, $n=7$; decentralized preparations, $n=8)$. A, Time-to-the peak current as a function of membrane potential for activation of $I_{\mathrm{A}}$ in PD neurons under control conditions (open circles) and in decentralized preparations (filled circles). The time-to-peak current did not differ significantly between the two conditions. $B, C$, During a maintained voltage pulse, $I_{\mathrm{A}}$ decays with two time constants, $\tau_{1}$ (fast) and $\tau_{2}$ (slow). Both time constants did not differ significantly between control conditions and decentralized preparations, as demonstrated for $\tau_{1}(B)$ and $\tau_{2}(C)$ for a voltage pulse to $+50 \mathrm{mV}$. $D$, Conductance-voltage curves for activation (circles) and inactivation (squares) of $I_{\mathrm{A}}$ under control conditions (open symbols) and in decentralized preparations (filled symbols). Values are calculated as a fraction of the maximal conductance under control conditions in each experiment. The activation curves were generated from peak currents after a maximally de-inactivating prestep to $-120 \mathrm{mV}$. The curves are fits to a third-order Boltzmann relation (Eq. 1, Materials and Methods) with the following parameters: control, $V_{\text {act }}=-41.7 \mathrm{mV}$, $s=-17.7 \mathrm{mV}$; decentralized, $V_{\text {act }}=-38.2 \mathrm{mV}$, $s=-18.9 \mathrm{mV}$. The curves for steady-state inactivation were generated from peak currents to voltage pulses to $+50 \mathrm{mV}$ after the neurons were held at the indicated potential (prepulse) for 1.5 sec. The curves are fits to a first-order Boltzmann relation (Eq. 1, Materials and Methods), with the following parameters: control, $V_{\text {inact }}=-63.2$ $\mathrm{mV}, s=6.0 \mathrm{mV}$; decentralized, $V_{\text {inact }}=-61.3$

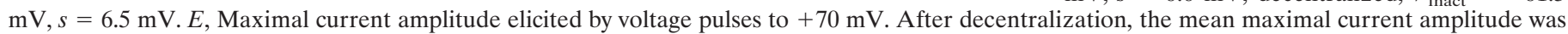
significantly increased by $43.4 \%$, from $313.6 \pm 24.3 \mathrm{nA}$ to $449.6 \pm 27.7 \mathrm{nA}\left({ }^{*} p<0.01\right)$.

Baro and Harris-Warrick, 1998). $I_{\mathrm{A}}$ is therefore an excellent current to monitor changes in intrinsic membrane properties that occur in response to long-term as well as short-term experimental perturbations. In this study, we focused on the expression of $I_{\mathrm{A}}$ in the PD neurons, which, together with the AB interneuron, serve as the predominant pacemaker neurons for the pyloric network. Our immunocytochemical results suggest that the long-term absence of modulatory inputs to the STG in organ culture leads to a substantial increase in the expression of shal channels. Voltageclamp measurements of $I_{\mathrm{A}}$ in long-term decentralized PD neurons confirmed that this enhanced staining reflects an increase in functional $I_{\mathrm{A}}$ expression. The overall morphology of the PD neurons, as assessed by confocal microscopy of dye-injected neurons, was not changed by long-term decentralization (our unpublished observations). Together, these data indicate that the prolonged absence of modulatory inputs to the pyloric network results in the de novo synthesis and/or redistribution of at least one type of channel that is implicated in the control of neuronal firing patterns. This in turn suggests that modulatory input plays an important role in the long-term maintenance of the biophysical characteristics of these neurons. There are two mechanisms by which this long-term effect could occur. First, modulatory inputs could directly affect gene expression via second messengermediated signal transduction pathways, leading to altered regulation of transcription (Jonas and Kaczmarek, 1999). Alternatively, the change in expression could arise indirectly from changes in ongoing activity of the neurons. Removal of modulatory inputs, for example, causes a dramatic change in the firing patterns of pyloric neurons, which in turn could alter activity- dependent plasticity (Turrigiano et al., 1994, 1995; Golowasch et al., 1999a,b), ultimately leading to new patterns of gene expression.

In addition to classical short-term regulation, synaptic inputs are known to exert persistent and long-term influences on their postsynaptic targets. Examples include anterograde regulation of the distribution and density of ligand-gated ion channels (Fambrough, 1979; Beam et al., 1985; Angelides, 1986). Additionally, presynaptic inputs have been shown to regulate sustained levels of target cell excitability (Traynor et al., 1992) and transmitter synthesis (Hyatt-Sachs et al., 1993) and to control gene expression in central neurons as well as muscle (Martinou and Merlie, 1991; Weiser et al., 1994; Fawcett et al., 2000). In the present case, however, the controlling inputs are not conventional presynaptic neurons; rather, they are neuromodulatory inputs with widespread short-term influences on an entire network, and are mediated by actions on a wide array of membrane conductances, including classical synaptic conductances and voltage-dependent channels that are implicated in membrane oscillations.

Using a combination of molecular and electrophysiological techniques, Baro et al. (1996b, 1997, 2000) have shown that, in a related decapod crustacean species, the California spiny lobster (Panulirus interruptus), two Shaker family genes, shaker and shal, can generate A-type potassium currents. However, three lines of evidence indicate that the somatic $I_{\mathrm{A}}$ results almost entirely from the activation of shal channels, rather than from a mixture of shaker and shal: (1) the similarity of $I_{\mathrm{A}}$ recorded in voltageclamped pyloric neurons to $I_{\mathrm{A}}$ recorded in Xenopus oocytes injected with Panulirus shal mRNA (Baro et al., 1996b, 1997); (2) 
the quantitative and linear relationship between the number of shal transcripts and the magnitude of $I_{\mathrm{A}}$ in different pyloric neurons (Baro et al., 1997), and (3) the specific localization, using immunocytochemistry, of shal but not shaker proteins in the somatic and neuritic membranes of pyloric neurons and a quantitative relation between the degree of shal protein labeling and shal transcription levels (Baro et al., 2000). The $I_{\mathrm{A}}$ that we recorded in Homarus pyloric neurons closely resembled the Panulirus $I_{\mathrm{A}}$ in its voltage dependence and time constants, suggesting that it, too, is encoded by the shal gene.

Our experiments show a significant postdecentralization increase in shal-like immunoreactivity in some STG neurons, and specifically in PD neurons. This de novo expression involved a significant increase in shal labeling on PD neurites and, for the first time, the appearance of detectable shal protein on the somatic membrane. However, the absence of stained PD somata in control ganglia does not necessarily reflect a complete lack of functional shal channels. Instead, it might reflect levels of shal protein below the detection threshold of the antibody. This possibility is supported by our voltage-clamp experiments, which revealed a sizeable $I_{\mathrm{A}}$ in nondecentralized control PD neurons (see also Kloppenburg et al., 1999). Additionally, because the antibody we used was generated to the shal channel in Panulirus, rather than Homarus, the apparent differences in intensity of shal-like staining might reflect differences in antibody affinity for the shal channels between these two species.

Because the antibody used here is also known to label shal proteins in glial cells (Baro et al., 2000), it is possible that the postdecentralization increase in shal staining reflects de novo channel expression in glial cells surrounding PD neuron somata, rather than in the soma membrane itself. However, although we cannot exclude this possibility, the simplest, most parsimonious explanation for our voltage-clamp data showing that PD neuron $I_{\mathrm{A}}$ increases concomitantly with shal-like staining in long-term decentralized ganglia is that at least part of the observed increase in staining is attributable to an increase in functional neuronal shal channels.

The only $I_{\mathrm{A}}$ parameter that changed in long-term isolated STGs relative to control ganglia was the maximal conductance. Because this increase was not associated with changes in either voltage or kinetic parameters, we concluded that the postdecentralization plasticity in $I_{\mathrm{A}}$ is attributable principally to changes in shal expression rather than changes in which gene encodes $I_{\mathrm{A}}$ or in expression of auxiliary subunits which modify $I_{\mathrm{A}}$ properties (An et al., 2000).

In terms of recovery of rhythmic activity, a postdecentralization increase in shal potassium channels seems somewhat counter-intuitive because an enhancement of $I_{\mathrm{A}}$ would be expected to impede, rather than promote, neuronal oscillation. However, although our study has focused on changes in the expression of a single channel type in one category of pyloric neuron (PD), it can be expected that other types of channels will change in parallel with shal in response to the prolonged absence of modulatory input. Indeed, other evidence, from studies of both dissociated cells (Turrigiano et al., 1994, 1995) and isolated STGs in organ culture (Thoby-Brisson and Simmers, 1998, 2000), suggests that membrane conductances in pyloric neurons change as an ensemble. Thus, it would be enlightening to extend our analysis to the other currents that contribute to the rhythmogenic character of the PD neurons. Because differences in the assemblage of currents present in identified neurons are responsible for specific differences in cell properties that are expressed by those neurons in different preparations including vertebrates (Rudy et al., 1999; Baro et al., 2000), it would also be enlightening to examine the extent to which the same or different currents in other pyloric neurons are altered as a result of long-term decentralization. For example, our data show that increases in somatic shal labeling are only seen in $\sim 20 \%$ of STG neurons; presumably the remaining neurons either do not compensate for the loss of modulatory input, or do so by altering other currents or by altering shal channels in other parts of the cell.

The extent to which modulatory inputs control their targets on a long-term basis may differ substantially between species as well as between individual neurons. The postdecentralization changes observed here in Homarus, for example, differ substantially from those previously reported in two other crustacean species, the crab Cancer borealis and the spiny lobster Jasus lalandii. In both Cancer and Jasus, rhythmic activity in the pyloric network ceases completely after decentralization, and a tri-phasic pattern returns only after a period of hours to days (Thoby-Brisson and Simmers, 1998; Golowasch et al., 1999a,b). In contrast, the PD neurons in Homarus lose rhythmicity for only minutes to hours after decentralization, whereas other circuit elements fall silent within $1 \mathrm{hr}$ and never recover bursting activity. Among the possible explanations for these interspecies differences are differences in the nature of the modulatory inputs and/or the extent to which a given modulatory input influences the many neural membrane conductances in each species. Understanding such diversity might enable us to elucidate more fully the mechanisms that underlie the role of modulators both in the short-term regulation and in the long-term maintenance of cellular properties in neural networks of the adult nervous system.

\section{REFERENCES}

An WF, Bowlby MR, Betty M, Cao J, Ling H-P, Mendoza G, Hinson JW, Mattson KI, Strassle BW, Trimmer JS, Rhodes KJ (2000) Modulation of A-type potassium channels by a family of sensors. Nature 403:553-556.

Angelides KJ (1986) Fluorescently labelled $\mathrm{Na}^{+}$channels are localized and immobilized to synapses of innervated muscle fibres. Nature 321:63-66.

Armstrong CM, Bezanilla F (1974) Charge movement associated with the opening and closing of the activation gates of the $\mathrm{Na}^{+}$channels. J Gen Physiol 63:533-552.

Baro DJ, Harris-Warrick RM (1998) Differential expression and targeting of $\mathrm{K}+$ channel genes in the lobster pyloric central pattern generator. Ann NY Acad Sci 860:281-295.

Baro DJ, Cole CL, Harris-Warrick RM (1996a) RT-PCR analysis of shaker, shab, shaw, and shal gene expression in single neurons and glial cells. Receptors Channels 4:149-159.

Baro DJ, Coniglio LM, Cole CL, Rodriguez HE, Lubell JK, Kim MT, Harris-Warrick RM (1996b) Lobster shal: comparison with Drosophila shal and native potassium currents in identified neurons. J Neurosci 16:1689-1701.

Baro DJ, Levini RM, Kim MT, Willms AR, Lanning CC, Rodriguez HE, Harris-Warrick RM (1997) Quantitative single-cell-reverse transcription-PCR demonstrates that A-current magnitude varies as a linear function of shal gene expression in identified stomatogastric neurons. J Neurosci 17:6597-6610.

Baro DJ, Ayali A, French L, Scholz NL, Labenia J, Lanning CC, Graubard K, Harris-Warrick RM (2000) Molecular underpinnings of motor pattern generation: differential targeting of shal and shaker in the pyloric motor system. J Neurosci 20:6619-6630.

Beam KG, Caldwell JH, Campbell DT (1985) Na channels in skeletal muscle concentrated near the neuromuscular junction. Nature 313:588-590.

Bidaut M (1980) Pharmacological dissection of the pyloric network of the lobster stomatogastric ganglion using picrotoxin. J Neurophysiol 44:1089-1101.

Combes D, Simmers J, Nonnotte L, Moulins M (1993) Tetrodotoxinsensitive dendritic spiking and control of axonal firing in a lobster mechanoreceptor neurone. J Physiol (Lond) 460:581-602.

Connor JA, Stevens CF (1971) Voltage clamp studies of a transient outward membrane current in gastropod neural somata. J Physiol (Lond) 213:21-30. 
Fambrough DM (1979) Control of acetylcholine receptor in skeletal muscle. Physiol Rev 59:165-227.

Fawcett JP, Alonso-Vanegas MA, Morris SJ, Miller FD, Sadikot AF, Murphy RA (2000) Evidence that brain-derived neurotrophic factor from pre-synaptic nerve terminals regulates the phenotype of calbindin-containing neurons in the lateral septum. J Neurosci 20:274-282.

Fénelon VS, Baro DJ, Harris-Warrick RM, Meyrand P, Simmers J (1998a) Plasticity of shal potassium channel expression in lobster stomatogastric neurons during development and after long-term decentralization. Soc Neurosci Abstr 24:1894.

Fénelon VS, Casanovas B, Simmers J, Meyrand P (1998b) Development of rhythmic pattern generators. Curr Opin Neurobiol 8:705-709.

Fischbach GD, Rosen KM (1997) ARIA: a neuromuscular junction neuregulin. Annu Rev Neurosci 20:429-458.

Golowasch J, Marder M (1992) Ionic currents of the lateral pyloric neuron of the stomatogastric ganglion of the crab. J Neurophysiol 67:318-331.

Golowasch J, Abbott LF, Marder E (1999a) Activity dependent regulation of potassium currents in the stomatogastric ganglion of the crab, Cancer borealis. J Neurosci 19:RC33(1-5).

Golowasch J, Casey M, Abbott LF, Marder E (1999b) Network stability from activity dependent regulation of neuronal conductances. Neural Comput 11:1079-1096.

Graubard K, Hartline DK (1991) Voltage clamp analysis of intact stomatogastric neurons. Brain Res 557:241-254.

Harris-Warrick RM, Marder E (1991) Modulation of neural networks for behavior. Annu Rev Neurosci 14:39-57.

Harris-Warrick RM, Marder E, Selverston AI, Moulins M (1992) Dynamic biological networks: the stomatogastric nervous system. Boston: MIT.

Harris-Warrick RM, Coniglio LM, Barazangi N, Gluckenheimer J, Gueron S (1995a) Dopamine modulation of transient potassium current evokes phase shifts in a central pattern generator network. J Neurosci 15:342-358.

Harris-Warrick RM, Coniglio LM, Levini RM, Gueron S, Gluckenheimer J (1995b) Dopamine modulation of two subthreshold currents produces phase shifts in activity of an identified motoneuron. J Neurophysiol 74:1404-1420.

Harris-Warrick RM, Johnson BR, Peck JH, Kloppenburg P, Ayali A, Skarbinski J (1998) Distributed effects of dopamine modulation in the crustacean pyloric network. Ann NY Acad Sci 860: 155-167.

Hartline DK, Graubard K (1992) Cellular and synaptic properties in the crustacean stomatogastric nervous system. In: Dynamic biological networks: the stomatogastric nervous system. (Harris-Warrick RM, Marder E, Selverston A, Moulins M, eds), pp 31-85. Boston: MIT.

Hodgkin AL, Huxley AF (1952) A quantitative description of membrane current and its application to conduction and excitation in nerve. J Physiol (Lond) 117:500-544.

Hyatt-Sachs H, Schreiber RC, Bennet TA, Zigmond RE (1993) Phenotypic plasticity in adult sympathetic ganglia in vivo: effects of deafferentation and axotomy on the expression of vasoactive intestinal peptide. J Neurosci 13:1642-1653.

Jonas EA, Kaczmarek LK (1999) The inside story: subcellular mechanisms of neuromodulation. In: Beyond neurotransmission. (Katz P, ed) pp 83-120. New York: Oxford UP.

Kloppenburg P, Levini RM, Harris-Warrick RM (1999) Dopamine modulates two potassium currents and inhibits the intrinsic firing properties of an identified motor neuron in a central pattern generator network. J Neurophysiol 81:29-38.

Le Feuvre Y, Fénelon VS, Meyrand P (1999) Removal of central inputs unmasks multiple adult neural networks from a single embryonic network. Nature 402:660-664.

Lupa MT, Krzemien DM, Schaller KL, Caldwell JH (1995) Expression and distribution of sodium channels in short- and long-term denervated rodent skeletal muscles. J Physiol (Lond) 483:109-118.

Marder E, Calabrese RL (1996) Principles of rhythmic motor pattern generation. Physiol Rev 76:687-717.

Martinou JC, Merlie JP (1991) Nerve-dependent modulation of acetylcholine receptor e-subunit gene expression. J Neurosci 11:1291-1299.

Miller JP, Selverston AI (1979) Rapid killing of single neurons by irradiation of intracellularly injected dye. Science 206:702-704.

Pearson KG (1993) Common principles of motor control in vertebrates and invertebrates. Annu Rev Neurosci 16:265-297.

Peck JH, Nakanishi ST, Yaple RA, Harris-Warrick RM (1999) Amine modulation of the transient potassium current $\left(\mathrm{I}_{\mathrm{A}}\right)$ in the $\mathrm{AB}$, IC and VD neurons of the lobster. Soc Neurosci Abstr 25:1646.

Rudy B, Chow A, Lau D, Amarillo Y, Ozaita A, Saganich M, Moreno H, Nadal MS, Hernandez-Pineda R, Hernandez-Cruz A, Erisir A, Leonard C, Vega-Saenz de Miera E (1999) Contribution of Kv3 channels to neuronal excitability. Ann NY Acad Sci 868:304-343.

Sillar KT, Wedderburn JF, Simmers AJ (1992) Modulation of swimming rhythmicity by 5 -hydroxytryptamine during post-embryonic development in Xenopus laevis. Proc R Soc Lond B Biol Sci 250:107-114.

Sillar KT, Woolston AM, Wedderburn JF (1995) Involvement of brainstem serotonergic interneurons in the development of a vertebrate spinal locomotor circuit. Proc R Soc Lond B Biol Sci 259:65-70.

Simmers J, Meyrand P, Moulins M (1996) Modulation and dynamic specification of motor rhythm-generating circuits in Crustacea. J Physiol (Paris) 89:195-208.

Stein PSG, Grillner S, Selverston AI, Stuart D (1997) Neurons, networks, and behavior. Boston: MIT.

Thoby-Brisson M, Simmers J (1998) Neuromodulatory inputs maintain expression of a lobster pattern-generating network in a modulationdependent state: evidence from long-term decentralization in vitro. J Neurosci 18:2212-2225.

Thoby-Brisson M, Simmers J (2000) Transition to endogenous bursting after long-term decentralization requires de novo transcription in a critical time window. J Neurophysiol 84:596-599.

Tierney AJ, Harris-Warrick RM (1992) Physiological role of the transient potassium current in the pyloric circuit of the lobster stomatogastric ganglion. J Neurophysiol 67:599-609.

Traynor P, Dryden WF, Smith PA (1992) Trophic regulation of action potential in bullfrog sympathetic neurons. Can J Physiol Pharmacol $70: 826-834$.

Turrigiano G, Abbott LF, Marder E (1994) Activity-dependent changes in the intrinsic properties of cultured neurons. Science 264:974-977.

Turrigiano G, LeMasson G, Marder E (1995) Selective regulation of current densities underlies spontaneous changes in the activity of cultured neurons. J Neurosci 15:3640-3652.

Weiser M, Backer H, Joh TH (1994) Gene expression in central cholinergic neurons in response to axotomy and deafferentiation. Synapse $16: 81-92$. 